\title{
CFD SIMULATION OF AIRFLOW DISTRIBUTION IN A HEAT PUMP-ASSISTED DEEP-BED PADDY DRYER
}

\author{
M. A. Reshaka Kavindi'1, K. S. P. Amaratunga ${ }^{1, *}$, E. M. A. C. Ekanayake², \\ A. J. Fernando ${ }^{3}$, A. M. S. K. Abesinghe ${ }^{1}$ \\ ${ }^{1}$ Department of Agricultural Engineering, Faculty of Agriculture, University of Peradeniya, Kandy, Sri Lanka. \\ 2 Postgraduate Institute of Agriculture, University of Peradeniya, Kandy, Sri Lanka. \\ ${ }^{3}$ Department of Agricultural Engineering and Soil Science, Faculty of Agriculture, Rajarata University of Sri Lanka, Puliyankulama, Anuradhapura, Sri \\ Lanka. \\ * Correspondence: sanath.amaratunga@gmail.com.
}

\section{HighLights}

- Uneven drying is an inevitable drawback when using heat pump-based deep-bed dryers in commercial drying industries.

- Understanding the drying behavior of the heat pump-based deep-bed dryers is important to optimize the drying technology.

- COMSOL Multiphysics is a very helpful tool as it can be used to predict the drying behavior.

\begin{abstract}
Heat pump dryers are widely used in drying agricultural products because of its capability in drying products at comparatively lower temperatures in commercial scale. However, deep-bed heat pump drying (HPD) leads to uneven drying because of its poor airflow distribution in the drying chamber. Optimizing the proper design of a heat pump dryer system may reduce the non-uniformity of drying and increases dryer efficiency. This study aimed to investigate the airflow distribution in a deep bed of rough rice dried with a heat pump using Computational Fluid Dynamics (CFD). The NavierStokes equation, Heat transfer equation, and Fick's Law were used in the mathematical models for simulation of air velocity, temperature, and relative humidity respectively. COMSOL Multiphysics simulation program v5.4 solved all the models with the boundary conditions of inlet velocity, inlet temperature, and drying air moisture content. The simulation was used to predict the temperature and the humidity of drying air at three different dryer locations during the drying process. Finally, the simulated data were verified using experimental results. The values of relative error and mean relative deviation for drying air temperature in paddy bed were less than $\pm 18.05 \%, 13.52 \%$. Relative error and mean relative error for air moisture in paddy bed were less than $\pm 15.83 \%$ and $14.44 \%$, respectively. The results indicated that the simulation model developed could effectively use for predicting the air temperature and air relative humidity with a reasonable accuracy.
\end{abstract}

Keywords. CFD simulation, COMSOL Multiphysics, Heat pump drying.

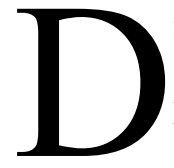
rying is very important unit operation in food industry which is done to increase the shelf life, preservation, improve the appearance, lower the shipping weights, reduce the packaging costs, retain original flavor, and maintain nutritional values (Salehi, 2021). Generally, moisture content should be effectively controlled to ensure food quality during the storage process. Specially in case of paddy, deep bed drying method is commonly used to dry deep layers of grains (Ranjbaran et al., 2014). Deep-bed drying has been investigated for many years. The non-uniformity in the bed, bed height variation during drying, varying air conditions on each layer during drying affect the drying process, and reduce the product quality (Liu et al.,

Submitted for review on 14 January 2021 as manuscript number 14483; approved for publication as a Research Article and as part of the Computer Modeling and Statistics for Agriculture Collection by the Information Technology, Sensors, \& Control Systems of ASABE on 17 September 2021.
2015). Even though conventional hot air dryers are widely used, it includes high energy costs, high dryer temperature, and long drying time, low quality output (Salehi, 2021). In order to solve these problems, heat pump-assisted deep bed drying technology has been assessed in recently studies (Colak and Hepbasli, 2009; Patel and Kar, 2012; Kivevele and Huan, 2014). Heat pump drying is superior to conventional drying methods for several reasons: high-quality output, heat recovery during the drying process, ability to precisely control the drying conditions low energy consumption, high thermal efficiency, and high drying performance (Zhang et al., 2017). When these dryers are commercially applied, it is very important to study moisture and temperature distribution through deep bed to improve and optimize the drying process. Mathematical modeling and computer simulation of paddy drying have been used to minimize the cost and time required for experiments which need to understand the all of thermal and physicochemical phenomena associated with drying process (Sitompul and Widiasa, 2001; ElGamal et al., 2013; 
Ranjbaran et al., 2014; Liu et al., 2015; Salehi, 2021). Predicting the drying parameters such as temperature and moisture content could help for design more efficient dryers and improve the existing dryer designs (Zare and Chen, 2009). Many researchers have focused on developing mathematical models for deep-bed drying technologies (Ranjbaran et al., 2014; Sitompul and Widiasa, 2001; Zare et al., 2006; Liu et al., 2015; Ghiaus and Gavriliuc, 2007; Amantéa et al., 2013; Harchegani et al., 2012). But fewer researchers have used simulation software to develop the CFD models and predict the drying parameters (Ranjbaran et al., 2014; Liu et al., 2015; Sapto et al., 2015; ElGamal et al., 2013; Misha et al., 2015; Getahun et al., 2019; Salvatierra-Rojas et al., 2021).

The quality of grains may be deteriorated by the high temperature and rapid moisture losses during the drying time (Elgamal et al., 2017). Therefore, efficiency of dryer is related with temperature of air and exposure time, as well as the moisture transportation. In fact, the distribution of moisture and temperature through a deep bed grain dryer during drying is not specifically discussed. Rather of being measured experimentally, drying parameters were primarily estimated from fundamental equations. Furthermore, most of developed models for deep bed drying have been validated using experimental data of references. But it can be limited the main objectives due to applying the other's related results than their applications (Jia et al., 2000; Mandas and Habte, 2002; Chueaprasat and Chitsomboon, 2008; Naghavi et al., 2010; Ranjbaran et al., 2014; ElGamal et al., 2015; Sitompul et al., 2001).As a result, obtaining reliable data in grain drying studies is critical (Elgamal et al., 2017). Even though CFD modeling has been investigated for many drying techniques, there is a lack of CFD simulation applications for heat pump-assisted paddy dryers. Therefore, there is a need of applications of simulation techniques to investigate the temperature and moisture distribution through the heat pump-based grain bed during the drying process. In this study all the simulations were done by COMSOL software; heat transfer in fluid model by naiver stoke equation and transport of diluted species in fluid model by Fick's law were carried out to predict the temperature and relative humidity of drying air. 3D geometry of the chamber and its physical properties, considered during the simulation, was taken from a specific experiment conducted in an industry. The performance of simulations was compared with experimental data. This study's main goal was to develop a CFD simulation model for heat and mass transfer of drying air during a heat pump based deep-bed paddy drying.

\section{Materials ANd Methods \\ EXPERIMENTAL SETUP}

The dyer setup consists of a drying chamber and heat pump components such as the evaporator, condenser, compressor, and expansion valve (fig. 1). The drying chamber is an opened, circular type, deep bed dryer. The ambient air flows through the evaporator producing low moist, cold air. This air supplies to the condenser and produces heated air. This heated low moist air is supplied to the drying chamber for drying paddy. The air passes through the drying bed and

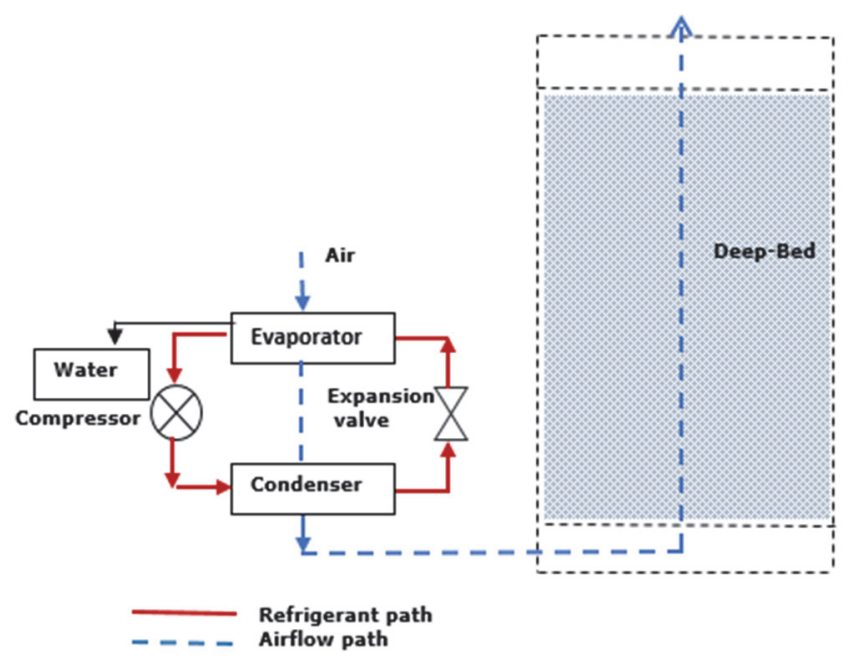

Figure 1. Schematic diagram of heat pump based deep-bed dryer.

the moisture laden warm air releases into the environment. The drying chamber dimensions were: $1.2 \mathrm{~m}$ in height and $0.95 \mathrm{~m}$ in diameter, and the thickness of the drying chamber wall was $0.002 \mathrm{~m}$ thick stainless steel. The inlet diameter of the drying chamber was $0.13 \mathrm{~m}$.

The experiments were conducted in the drying chamber at atmospheric pressure. The temperature and the relative humidity were measured during the paddy drying. AM2302 (wired DHT22) sensors were installed to measure the temperature and the relative humidity at (A1 to A11) as shown in figure 2 . Inlet air velocity was measured using a portable velocity meter (KURZ instruments, 440 series, Chatsworth, Calif.), and outlet velocity was measured using a Davis vane anemometer (Davis Instruments, A/2-4 in. standard model, Davis Instrument Mfg. Co., Baltimore, Md.). The experiments were conducted at constant inlet velocity of $24 \mathrm{~ms}^{-1}$ for heat pump paddy drying.

\section{CFD ANALYSIS}

The CFD analysis was carried using COMSOL Multiphysics software. The 3D geometry of the chamber was design in a COMSOL work plane. A mesh was generated and mathematical models were developed. The model predicted data were validated with the experimental data.

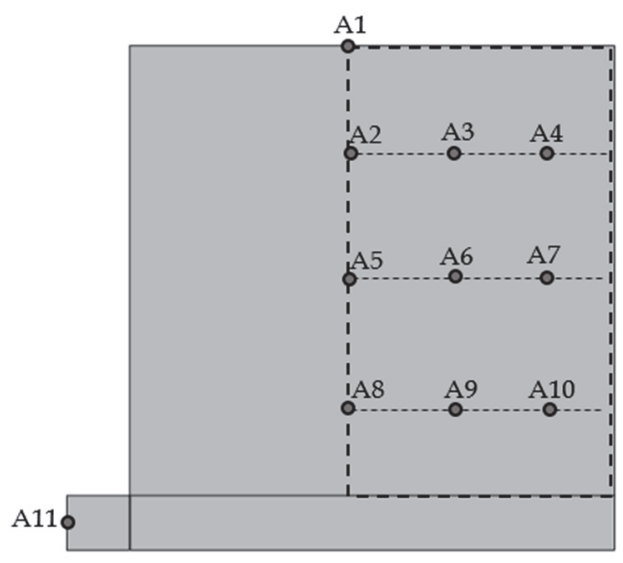

Figure 2. Sensor locations in the drying chamber. 


\section{Numerical Simulation}

The numerical computation of fluid transport employs conservation of mass, momentum, and turbulence model equations. The assumptions for the simulation were:

- The drying process in the drying chamber is adiabatic.

- The drying chamber is axisymmetric.

- Flow is incompressible.

- The flow is turbulent, two dimensional, and unsteady.

- The deep bed is a homogeneous porous media.

- Inflow and outflow boundaries are sufficiently far away from the region of intent to have minimal effect on flow

\section{Turbulent $k$ - $\varepsilon$ Model}

The turbulent flow, the k- $\varepsilon$ interface, was used for simulating single-phase air flows at high Reynold's numbers. The physics interface is suitable for incompressible flows and compressible flows at low Mach numbers (typically less than 0.3 ). The equations solved by the turbulent flow $\mathrm{k}-\varepsilon$ interface is the Navier-Stokes equation for conservation of momentum and the continuity equation for conservation of mass. Turbulence effects were modeled using the standard twoequation k- $\varepsilon$ model with realizability constraints. Flow close to walls was modeled using wall functions (COMSOL Reference Manual). Basic equations for single-phase fluid flow interface are based on the Navier-stoke equation simplified shown in equations 1 and 2 :

$$
\begin{gathered}
\frac{\partial \rho}{\partial \mathrm{t}}+\nabla \cdot(\rho \mathrm{u})=0 \\
\rho \frac{\partial \mathrm{u}}{\partial \mathrm{t}}+\rho(\mathrm{u} . \nabla) \mathrm{u}=\nabla \cdot\left[-\mathrm{pI}+\mu\left(\nabla \mathrm{u}+(\nabla \mathrm{u})^{\mathrm{T}}\right)\right]+\mathrm{F}
\end{gathered}
$$

\section{Brinkman Equation}

Brinkman equation interface (Kumar et al., 2016) was used to compute fluid velocity and pressure fields of singlephase flow in porous media of a deep-bed. The physics interface extends Darcy's law to describe the kinetic energy dissipation by viscous shear, similar to the Navier-Stokes equations. Fluids with varying density can be included at Mach numbers below 0.3 .

The momentum conservation equations 3 and 4 in Brinkman model are:

$$
\begin{gathered}
\nabla \cdot\left[-\mathrm{pI}+\mu \frac{1}{\varepsilon_{\mathrm{p}}}\left(\nabla \mathrm{u}+(\nabla \mathrm{u})^{\mathrm{T}}\right)\right] \\
-\left(\frac{\mu}{\mathrm{k}}+\beta_{\mathrm{F}}|\mathrm{u}|+\frac{\mathrm{Q}_{\mathrm{br}}}{\varepsilon_{\mathrm{p}}^{2}}\right) \mathrm{u}+\mathrm{F}=0 \\
(\rho \nabla \cdot \mathrm{u})=\mathrm{Q}_{\mathrm{br}}
\end{gathered}
$$

\section{Heat Transfer in Fluid}

The Heat transfer in fluids interface of COMSOL was used to model heat transfer by conduction, convection, and radiation. A fluid model is activated by default on all domains (COMSOL Reference Manual).

$$
\rho c_{p}\left(\frac{\partial T}{\partial t}+U . \nabla T\right)+\nabla \cdot q=Q+Q_{p}+Q_{v d}
$$

The second term of the right-side $\left(Q_{p}\right)$ in equation 5 is the work done by pressure changes which is the result of heating under adiabatic compression and some thermoacoustic effects. It is generally small for low match number flows.

$$
\mathrm{Q}_{\mathrm{p}}=\alpha_{\mathrm{p}} \mathrm{T}\left(\frac{\partial \mathrm{P}}{\partial \mathrm{t}}+\mathrm{u} . \nabla \mathrm{p}\right)
$$

The third term represents viscous dissipation in the fluid:

$$
Q_{v d}=\tau: \nabla u
$$

\section{Transport of Diluted Species in Porous Media}

Transport of diluted species in porous media model was used to transport solute in porous media for Brinkman model and turbulent model, since the implicitly related to the porous media's nature via the fluid flow equation in porous media. The main force for the transport phenomena is diffusion by Fick's law which shown in equation 8 . Transport and reaction of species in a gas, liquid, or solid can be handle by this model (Kumar et al., 2016).

The basic equation of Fick's law defined in equation 8 and derived equations used in the transport of diluted species model are shown in equations 9 and 10 .

$$
\begin{gathered}
\frac{\vartheta c}{\vartheta t}=D \partial^{2} C / \partial x^{2} \\
\varepsilon_{p} \frac{\partial c i}{\partial t}+c_{i} \frac{\partial \varepsilon_{p}}{\partial t}+\nabla . \Gamma i+u . \nabla c i=R i+S i \\
\Gamma i+u . c i=-\frac{\varepsilon_{p}}{\tau_{F, i}} D_{f, i} \nabla c i+u . c
\end{gathered}
$$

for constant porosity and constant diffusion, $R i=0$ and $c_{i} \frac{\partial \varepsilon_{p}}{\partial t}=0$ and $\nabla \cdot \Gamma i=-\nabla \cdot\left(\varepsilon_{p} D_{f, i} \nabla c i\right)=-\varepsilon_{p} D_{f, i} \nabla^{2} c i$. Therefore, the equations modified to the convection-diffusion equation 11 for constant porosity, constant diffusion, $R i$ $=0, S i=0$, and $\Gamma i=1$. The inlet boundary condition specifies initial moisture concentration, and the outlet boundary condition corresponds to free flow. No flux boundary conditions are specified at the transverse boundaries.

$$
\varepsilon_{p} \frac{\partial c i}{\partial t}+\mathrm{u} \cdot \nabla \mathrm{c}=\varepsilon_{p} D_{f, i} \nabla^{2} c i
$$

\section{Simulation Procedure}

The solid object was created in the work plane by combining the separate parts of the domain $(0.95 \mathrm{~m}$ diameter and $1.07 \mathrm{~m}$ height porous bed and $0.13 \mathrm{~m}$ free space from the bottom of the chamber to the wire mesh; $0.13 \mathrm{~m}$ diameter and $0.2 \mathrm{~m}$ long inlet) into structured hexahedral computational cells (fig. 3). The quality of geometry was examined 
by generating the mesh. The mesh was generated using several types of finite element models or topology (fig. 4). The free meshing time was $38.30 \mathrm{~s}$. User control mesh was selected. Due to the complexity of the mesh, the coarse type was selected. The maximum and minimum element sizes were 0.117 and $0.0352 \mathrm{~m}$, respectively. The maximum element growth rate was 1.4. Curvature factor and resolution of narrow regions 1 and 0.3 , respectively.

The study was focused on the pattern of the air stream in the drying chamber. Therefore, steady-state conditions were used. Half of the chamber was used to avoid the solver's complexity. The selected boundary conditions and surfaces are shown in figure 5 . The initial and boundary condition for simulation are shown in table 1 . The material bed's porosity was 0.3 , and the diffusion coefficient used in all simulations was $4 \times 10^{-8} \mathrm{~m}^{2} \mathrm{~s}^{-1}$.

The simulation steps were as follows: 1) stationary fluid flow study coupled with the Brinkman and turbulent equations; 2) time dependent study coupled with the heat and moisture transfer equations. The airflow in the porous zone was achieved by Brinkman and free space was considered to

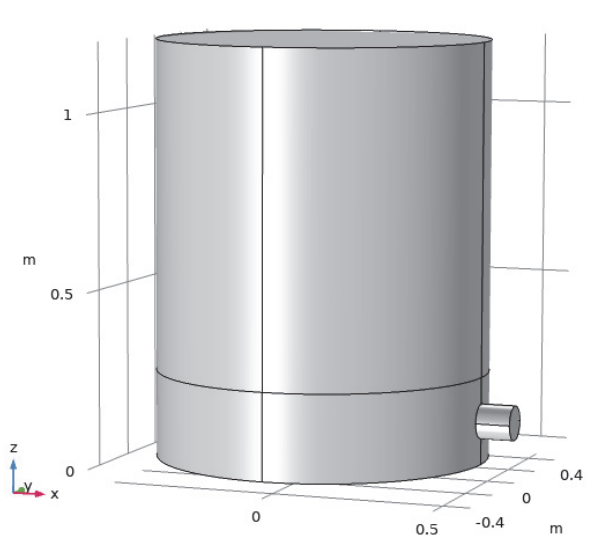

a

Figure 3. Computational domain of drying chamber.

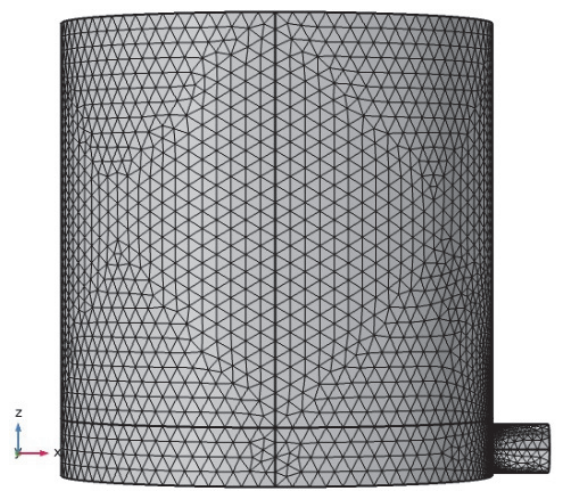

Figure 4. Mesh of drying chamber for simulation.

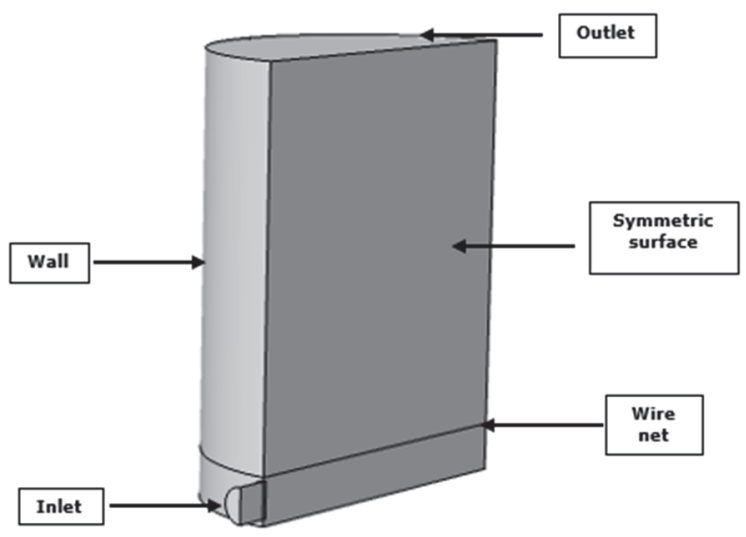

Figure 5. Boundary surfaces of the chamber.

be a turbulent model. The temperature of drying air was achieved through heat transfer in the fluid by considering dry air as a fluid of simulation. Moisture in the gas phase was considered as diluted species. The diluted species transport in porous media was activated in COMSOL to calculate the relative humidity distribution of drying air in the bed. The temperature and the relative humidity were presented as the time-dependent variables.

\section{VALIDATION}

The obtained data were compared with the experimental results to validate the results of the numerical simulation. The simulation model performance was determined by calculating the relative error (RE) and the mean relative deviation (MRD) using equation 12 and equation 13, which was the same approach used by Zare et al. (2006).

$$
\begin{gathered}
E=\frac{\left(M_{j}-\hat{M}_{j}\right)}{M_{j}} \times 100 \\
M R D=\left[\frac{1}{n} \sum_{j=1}^{n}\left(\frac{M_{j}-\hat{M}_{j}}{M_{j}}\right)^{2}\right]^{0.5} \times 100
\end{gathered}
$$

where $M_{j}$ and $\hat{M}_{j}$ indicate the $\mathrm{j}^{\text {th }}$ experimental and predicted moisture content or temperature of air (dry basis), respectively, and $\mathrm{n}$ is the number of measurements in each experiment.

\section{RESULTS AND DisCUSSION}

Proposed simulation method is tested for predicting the temperature and relative humidity of airflow on COMSOL environment. The results are implemented at Intel ${ }^{\mathbb{R}} \mathrm{Core}^{\mathrm{TM}}$ i3-3110M CPU @ 2.40GHz, 8.00 GB RAM, and 64-bit operating system. A typical contour of simulation process for

\begin{tabular}{|c|c|c|c|c|c|c|}
\hline & $\begin{array}{c}\text { Average Inlet } \\
\text { Airflow } \\
\left(\mathrm{ms}^{-1}\right)\end{array}$ & $\begin{array}{c}\text { Inlet } \\
\text { Air Temperature } \\
\left({ }^{\circ} \mathrm{C}\right)\end{array}$ & $\begin{array}{c}\text { Outlet } \\
\text { Air Temperature } \\
\left({ }^{\circ} \mathrm{C}\right)\end{array}$ & $\begin{array}{c}\text { Inlet Air Relative } \\
\text { Humidity } \\
(\%)\end{array}$ & $\begin{array}{c}\text { Outlet Air Relative } \\
\text { Humidity } \\
(\%)\end{array}$ & $\begin{array}{l}\text { Temperature of the } \\
\text { Surrounding } \\
\left({ }^{\circ} \mathrm{C}\right)\end{array}$ \\
\hline Initial & 24 & 56 & 25.9 & 23 & 82.1 & 26.8 \\
\hline Final & & 58.2 & 25.3 & 22.2 & 85.7 & 26.5 \\
\hline
\end{tabular}

Table 1. Initial conditions of the simulation. 
(a) velocity, (b) temperature, and (c) relative humidity of drying air after 30 min drying with the initial parameters and respected values in table 1 is provided in figure 6 . Simulation results explains the non-uniform distribution of temperature and relative humidity during deep-bed drying. Due to the rapid change in the cross-section of the plenum chamber, the air approaching the bed had higher velocity and temperature at the bottom. Same phenomenon has described in Ranjbaran et al. (2014) as it is a result of higher vapor pressure gradient between grains and surrounding. Due to the packed material bed, lower velocity could be obtained in the middle $\left(0.27 \mathrm{~ms}^{-1}\right)$ than the chamber edge area $\left(0.282 \mathrm{~ms}^{-1}\right)$ within the same layer. The highest velocity was $0.33 \mathrm{~ms}^{-1}$ at the bottom of the chamber, following $0.27 \mathrm{~ms}^{-1}$ in the middle and $0.256 \mathrm{~ms}^{-1}$ in the top layer. Further explanation has done with the results of validation tests.

The results of RE and MRD for air temperature and relative humidity are shown in table 2 . Three different bed depths of 75,45 , and $15 \mathrm{~cm}$ from the top of the chamber were predicted. Three-point sample values for each depth were evaluated with the experimental data, as summarize in table 2. For each point, 30 data values were predicted with $1 \mathrm{~min}$ time gap for 30 min drying period.

In many drying prediction studies reported, error between experimental measures and predicted parameters within $10 \%-15 \%$ is a satisfactory agreement (Madhiyanon et al., 2001; Sitompul et al., 2001; Kalbasi, 2003; Dimitriadis and Akritidis, 2004, Ranjbaran et al., 2014, Harchegani et al., 2012, Zare et al., 2006). As can be seen in table 2 the values of RE and MRD drying air temperature and humidity is around $\pm 15 \%$ or less, but only the $75 \mathrm{~cm}$ depth layer $32 \mathrm{~cm}$ away from center line point $\left(\mathrm{A}_{2}\right)$ shows quite higher RE for

Table 2. RE and MRD of air temperature and air relative humidity of different locations in HPD.

\begin{tabular}{|c|c|c|c|c|}
\hline & \multicolumn{2}{|c|}{ Air Temperature $\left({ }^{\circ} \mathrm{C}\right)$} & \multicolumn{2}{|c|}{ Air Relative Humidity (\%) } \\
\hline & $\begin{array}{c}\text { Relative } \\
\text { Error } \\
(\%)\end{array}$ & $\begin{array}{c}\text { Mean Relative } \\
\text { Deviation } \\
(\%)\end{array}$ & $\begin{array}{c}\text { Relative } \\
\text { Error } \\
(\%)\end{array}$ & $\begin{array}{c}\text { Mean Relative } \\
\text { Deviation } \\
(\%)\end{array}$ \\
\hline $\mathrm{A}_{2}$ & -18.05 & 12.35 & 2.039 & 3.63 \\
\hline $\mathrm{A}_{3}$ & -12.32 & 12.35 & -5.901 & 7.05 \\
\hline $\mathrm{A}_{4}$ & -15.15 & 15.41 & 2.215 & 3.91 \\
\hline $\mathrm{A}_{5}$ & -15.41 & 15.59 & 9.414 & 9.63 \\
\hline $\mathrm{A}_{6}$ & -15.56 & 15.83 & 13.52 & 14.44 \\
\hline $\mathrm{A}_{7}$ & -13.09 & 13.3 & 6.84 & 7.09 \\
\hline $\mathrm{A}_{8}$ & -4.27 & 4.51 & 3.198 & 3.29 \\
\hline $\mathrm{A}_{9}$ & -4.42 & 4.68 & 2.617 & 2.733 \\
\hline $\mathrm{A}_{10}$ & -1.21 & 2.04 & -4.172 & 4.27 \\
\hline
\end{tabular}

drying air temperature as $-18 \%$. Therefore, the HPD simulation describes the drying process with a reasonable accuracy. The deviation of simulated results from experimental data of moisture data can be due to simplification assumptions made when building the mathematical model, errors in measurement of input parameters, and the dryer's actual performance. Experimental and predicted values of drying air temperature in three different layers are illustrated in figure 7. As the bed height increases, the air temperature reduces. Moreover, as time passes, the hot air temperature of each layer gradually increases. Computer simulation values showed the same phenomena during drying.

Predicted values of drying air moisture content are determined by the interaction of heat medium temperature and air velocity in three different layers as shown in figure 8 . Initial conditions were used as in table 1 . At the initial stage of drying, hot air moisture content increased, and the increased amount was more in the middle layer.

However, moisture content of drying air in lower region is low when consider with the other layers. It is due to the very lower humidity condition of drying air which was provided by HPD. But with the time moisture content was increased due to the moisture transport from grains to the surrounding air. The relative humidity of inlet air was $23 \%$. It increased as it passed through the moist grains bulk. This can be seen in figure 8 . After 30 min of drying period, upper layer (A4, A2), air moisture was nearly $88 \%$. Center point of upper layer recorded as $81.7 \%$. These values are less than middle layer moisture contents of paddy bed. It is due to adsorption phenomena that exist in upper paddy at the initial stage of drying. That is, external moisture is migrated inward at that moment. Same phenomena has described in Ranjbaran et al. (2014). However relative error was calculated for 75, 45, and $15 \mathrm{~cm}$ depth layer and results showed as $-4.172 \% \sim 3.198 \%, \quad 6.84 \% \sim 13.52 \%$, and $-5.901 \%$ $2.215 \%$. Same time mean relative deviation was predicted. MRD for 75,45 , and $15 \mathrm{~cm}$ depth layers were $2.733 \% \sim 4.27 \%, 7.09 \% \sim 14.44 \%$, and $3.63 \% \sim 7.05 \%$. Due to calculated errors less than $15 \%$, simulation values are in the acceptable range (Park et al., 2002).

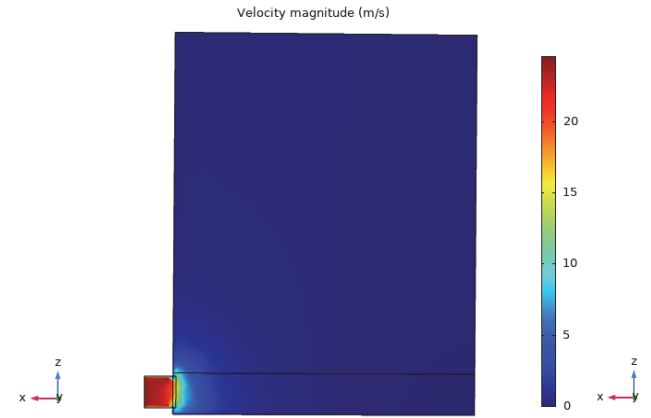

(a) velocity

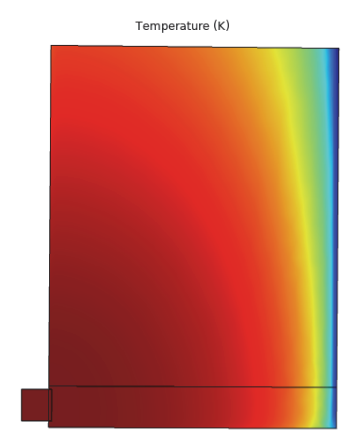

(b) temperature

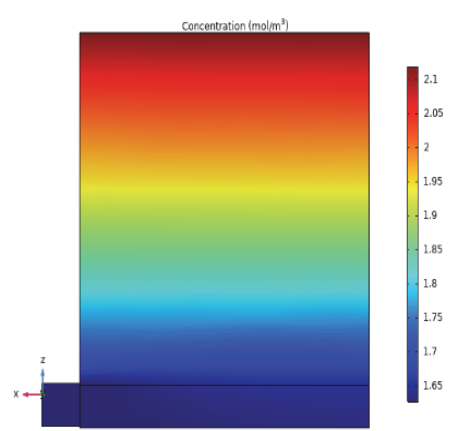

(c) relative humidity

Figure 6. Simulation profile after 30 min drying period of (a) velocity, (b) temperature, and (c) relative humidity for heat-pump drying chamber. 


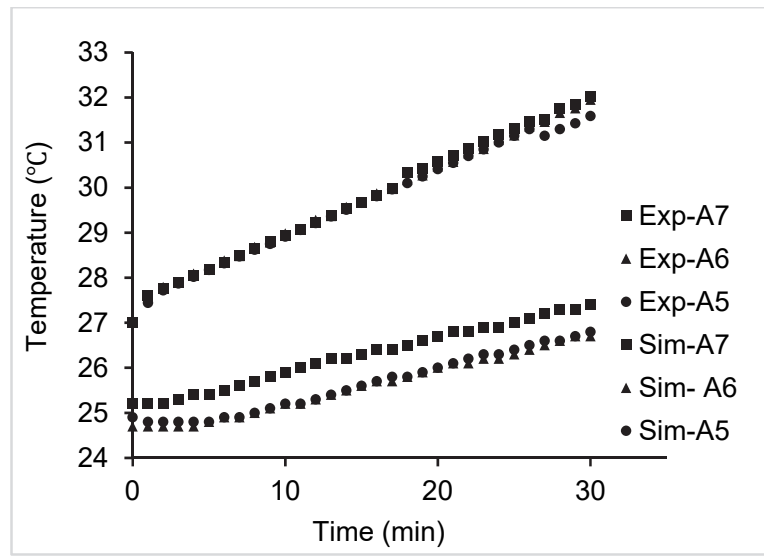

(a) $75 \mathrm{~cm}$ depth layer

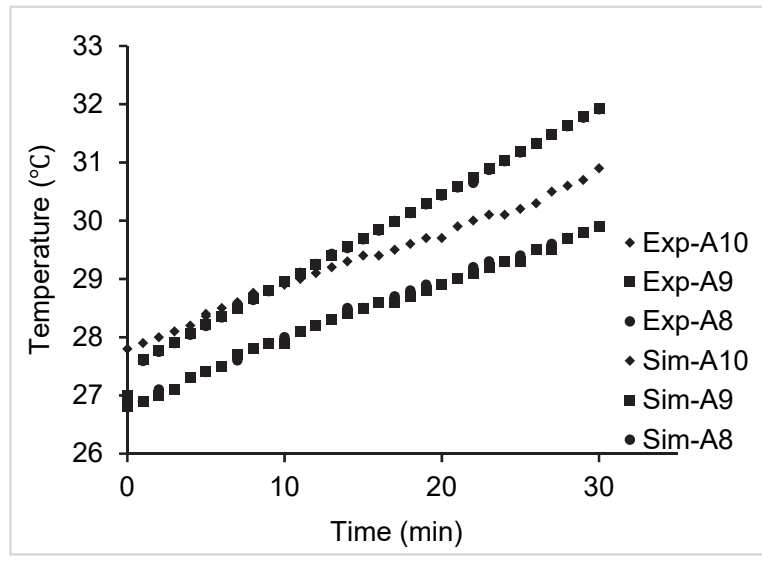

(b) $45 \mathrm{~cm}$ depth layer

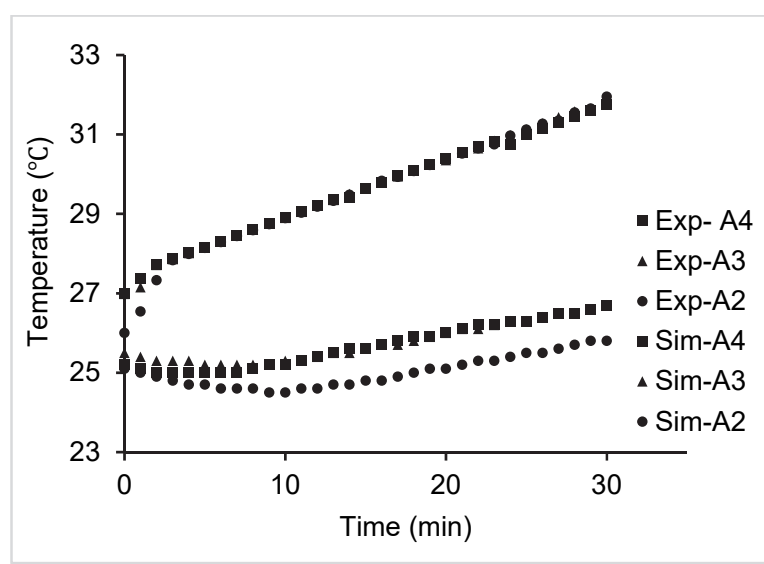

(c) $15 \mathrm{~cm}$ depth layer

Figure 7. Experimental (Exp.) and Simulated (Sim.) temperature profile for 15,45 , and $75 \mathrm{~cm}$ depth layer.

\section{CONCLUSiOnS}

In this article, commercial CFD software COMSOL Multiphysics was used to predict air flow distribution in the drying chamber by considering the product as porous media.

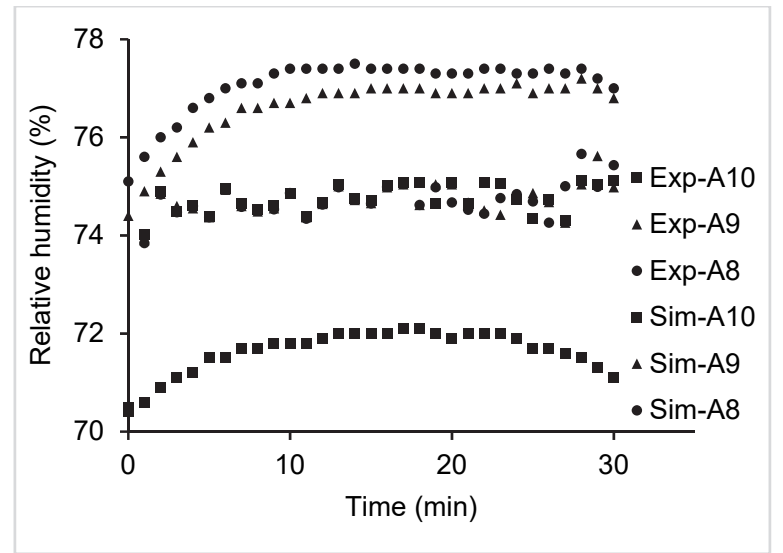

(a) $75 \mathrm{~cm}$ depth layer

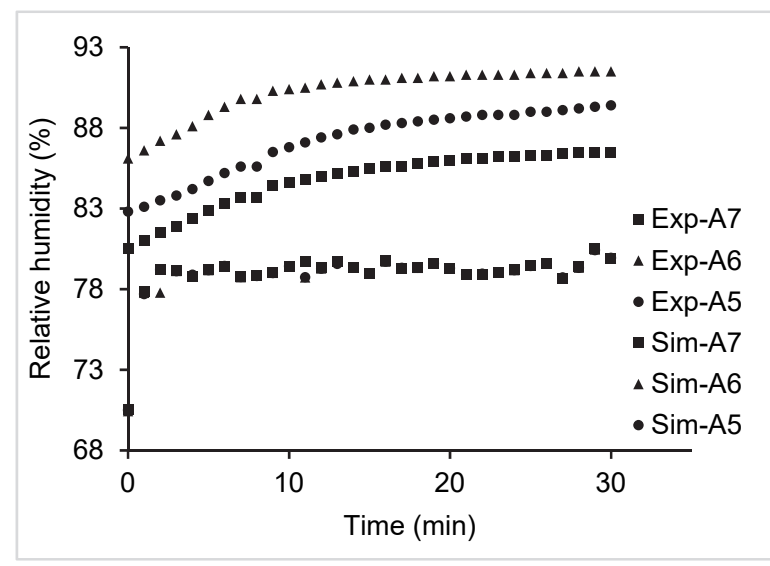

(b) $45 \mathrm{~cm}$ depth layer

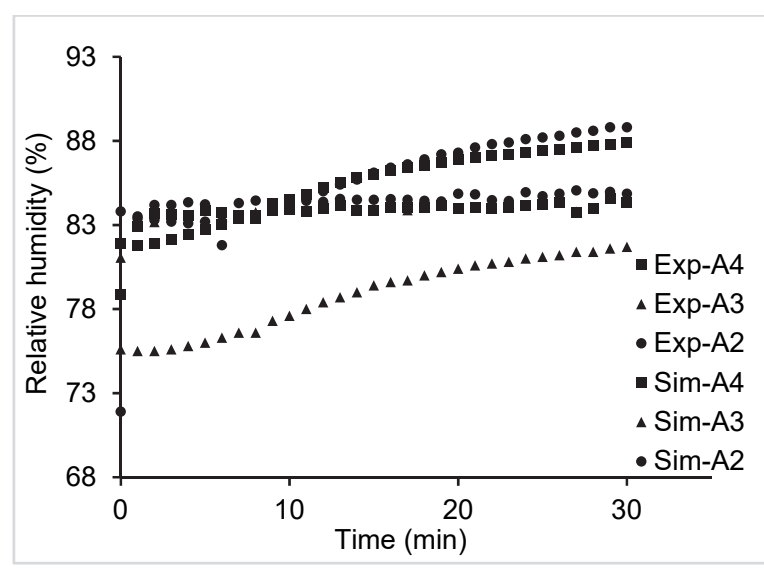

(c) $15 \mathrm{~cm}$ depth layer

Figure 8. Experimental (Exp.) and Simulated (Sim.) moisture profile for (a) $75 \mathrm{~cm}$, (b) $45 \mathrm{~cm}$, and (c) $15 \mathrm{~cm}$ depth layer.

The simulation results were compared with experimental data of the deep-bed drying of paddy. The obtained values of maximum relative error of simulation (RE) and mean relative deviation (MRD) for prediction of air temperature were less than $\pm 18.05 \%, 13.52 \%$, and for air relative humidity were less than $\pm 15.83 \%, 14.44 \%$, respectively. Therefore, 
the model predicted air temperature and the relative humidity at different locations were in good agreement with the experimental data. This article has covered heat pump assisted drying process simulation with the help of COMSOL software, with hope of this technique in future research, will produce optimization of the process that is more economical, productive, and less harmful to the environment.

\section{ACKNOWLEDGeMent}

The authors would like to acknowledge financial support of the Research Facilitation Fund(RFF) by the Postgraduate Institute of Agriculture, Sri Lanka.

\section{REFERENCES}

Amantea, R. P., Fortes, M., Martins, J. H., \& Ferreira, W. R. (2013). Numerical simulation techniques for optimizing thermodynamic efficiencies of cereal grain dryers. Drying Technol., 31(6), 672683. https://doi.org/10.1080/07373937.2012.753903

Chueaprasat, C., \& Chitsomboon, T. (2008). Numerical analysis of heat and moisture transfers in a rice grain. Proc. 22nd Conf. of Mechanical Engineering Network of Thailand, (pp. 15-17).

Colak, N., \& Hepbasli, A. (2009). A review of heat pump drying: Part 1 - Systems, models and studies. Energy Conversion Manag., 50(9), 2180-2186. https://doi.org/10.1016/j.enconman.2009.04.031

COMSOL Reference Manual. (n.d.). Retrieved from http//www.COMSOL Multiphysics.com

Dimitriadis, A. N., \& Akritidis, C. B. (2004). A model to simulate chopped alfalfa drying in a fixed deep bed. Drying Technol., 22(3), 479-490. https://doi.org/10.1081/DRT-120029994

ElGamal, R. A., Kishk, S. S., \& ElMasry, G. M. (2017). Validation of CFD models for the deep-bed drying of rice using thermal imaging. Biosyst. Eng., 161, 135-144. https://doi.org/10.1016/j.biosystemseng.2017.06.018

ElGamal, R., Ronsse, F., \& Pieters, J. (2013).Modeling deep-bed grain drying using Comsol Multiphysics. Proc. COMSOL Conf.

ElGamal, R., Ronsse, F., ElMasry, G., \& Pieters, J. G. (2015). Development of a multi-scale model for deep-bed drying of rice. Trans. ASABE, 58(3), 849-859. https://doi.org/10.13031/trans.58.10904

Getahun, E., Vanierschot, M., Gabbiye, N., Delele, M. A., Workneh, S., \& Gebrehiwot, M. (2019). Computational fluid dynamic modeling and simulation of red chili solar cabinet dryer. Proc. 4th Int. Conf. on Advancements of Science and Technology. https://doi.org/10.1007/978-3-030-43690-2_45

Ghiaus, A. G., \& Gavriliuc, R. (2007). Simulation of air flow and dehydration process in tray drying systems. UPB Sci. Bull.(69), 41-50.

Harchegani, M. T., Moheb, A., Sadeghi, M., Tohidi, M., \& Naghavi, Z. (2012). Experimental study of operating parameters affecting deep-bed drying kinetics of rough rice and comparing with a non-equalibrium mathematical model:. Agric. Eng. Int.: CIGR J., 14(4), 195-202.

Jia, C.-C., Sun, D.-W., \& Cao, C.-W. (2000). Mathematical simulation of temperature and moisture fields within a grain kernel during drying. Drying Technol., 18(6), 1305-1325. https://doi.org/10.1080/07373930008917778

Kalbasi, M. (2003). Heat and moisture transfer model for onion drying. Drying Technol., 21(8), 1575-1584. https://doi.org/10.1081/DRT-120024492
Kivevele, T., \& Huan, Z. (2014). A review on opportunities for the development of heat pump drying systems in South Africa. $S$. Afr. J. Sci., 110(5/6), 11. https://doi.org/10.1590/sajs.2014/20130236

Kumar, A., Pramanik, S., \& Mishra, M. (2016). COMSOL Multiphysics modeling in darcian and non-darcian porous media. Proc. COMSOL Conf., (pp. 20-21).

Liu, Z., Wu, Z., Wang, X., Song, J., \& Wu, W. (2015). Numerical simulation and experimental study of deep bed corn drying based on water potential. Math. Problems Eng., 2015. https://doi.org/10.1155/2015/539846

Madhiyanon, T., Soponronnarit, S., \& Tia, W. (2001). Industrialscale prototype of continuous spouted bed paddy dryer. Drying Technol., 19(1), 207-216. https://doi.org/10.1081/DRT100001362

Mandas, N., \& Habte, M. (2002). PH-Postharvest technology: Numerical simulation static-bed drying of barley. Biosyst. Eng., 82(3), 313-319. https://doi.org/10.1006/bioe.2002.0075

Misha, S., Mat, S., Rosli, M. A., Ruslan, M. H., Sopian, K., \& Salleh, E. (2015) Simulation of air flow distribution in a tray dryer by CFD. Proc. 10th Int. Conf. on Energy \& Environment. Recent Advances in Renewable Energy Sources, (pp. 126-135).

Naghavi, Z., Moheb, A., \& Ziaei-rad, S. (2010). Numerical simulation of rough rice drying in a deep-bed dryer using nonequilibrium model. Energy Conversion Manag., 51(2), 258-264. https://doi.org/10.1016/j.enconman.2009.09.019

Park, K. J., Vohnikova, Z., \& Brod, F. P. R. (2002). Evaluation of drying parameters and desorption isotherms of garden mint leaves (Mentha crispa L.). J. Food Eng., 51(3), 193-199. https://doi.org/10.1016/S0260-8774(01)00055-3

Patel, K. K., \& Kar, A. (2012). Heat pump assisted drying of agricultural produce: An overview. J. Food Sci. Technol., 49(2), 142-160. https://doi.org/10.1007/s13197-011-0334-z

Ranjbaran, M., Emadi, B., \& Zare, D. (2014). CFD Simulation of deep-bed paddy drying process and performance. Drying Technol., 32(8), 919-934. https://doi.org/10.1080/07373937.2013.875561

Salehi, F. (2021). Recent applications of heat pump dryer for drying of fruit crops: A review. Int. J. Fruit Sci., 21(1), 546-555. https://doi.org/10.1080/15538362.2021.1911746

Salvatierra-Rojas, A., Ramaj, I., Romuli, S., \& Muller, J. (2021). CFD-Simulink modeling of the inflatable solar dryer for drying paddy rice. Appl. Sci., 11(7), 3118. https://doi.org/10.3390/app11073118

Sapto, W. W., Wong, C. Y., Kamarul, A. M., \& Nurul Hidayah, A. (2015). CFD Simulation for tray dryer optimization.

Sitompul, J. P., Istadi, \& Widiasa, I. N. (2001). Modeling and simulation of deep-bed grain dryers. Drying Technol., 19(2), 269-280. https://doi.org/10.1081/DRT-100102903

Zare, D., \& Chen, G. (2009). Evaluation of a simulation model in predicting the drying parameters for deep-bed paddy drying. Comput. Electron. Agric., 68(1), 78-87. https://doi.org/10.1016/j.compag.2009.04.007

Zare, D., Minaei, S., Mohamad Zadeh, M., \& Khoshtaghaza, M. H. (2006). Computer simulation of rough rice drying in a batch dryer. Energy Conversion Manag., 47(18), 3241-3254. https://doi.org/10.1016/j.enconman.2006.02.021

Zhang, M., Chen, H., Mujumdar, A. S., Tang, J., Miao, S., \& Wang, Y. (2017). Recent developments in high-quality drying of vegetables, fruits, and aquatic products. Crit. Rev. Food Sci. Nutr., 57(6), 1239-1255.

https://doi.org/10.1080/10408398.2014.979280 
NOMENCLATURE

$\mathrm{T}$ air temperature $(\mathrm{K})$

MRD mean relative deviation (\%)

$\mathrm{RE}$ relative error $(\%)$

$\mathrm{RH}$ relative humidity (\%)

Q heat $\left(\mathrm{W} / \mathrm{m}^{3}\right)$

I fluid enthalpy $(\mathrm{J} / \mathrm{kg})$

$\mathrm{P} \quad$ pressure $(\mathrm{Pa})$

U velocity vector $(\mathrm{m} / \mathrm{s})$

F volume force vector $\left(\mathrm{N} / \mathrm{m}^{3}\right)$

D diffusion coefficient

$\mathrm{X}$ position in the chamber $(\mathrm{m})$

C vapor concentration $\left(\mathrm{mol} / \mathrm{m}^{3}\right)$

$\mathrm{Q}_{\mathrm{p}} \quad$ work is done by pressure changes $(\mathrm{W})$

$\mathrm{Q}_{\mathrm{vd}} \quad$ viscous dissipation in the fluid $\left(\mathrm{W} / \mathrm{m}^{3}\right)$

$\mathrm{Q}_{\mathrm{br}} \quad$ mass sink source $\left(\mathrm{kg} / \mathrm{m}^{3} . \mathrm{s}\right)$

Ri reaction rate of the $\mathrm{i}^{\text {th }}$ species

$\Gamma i$ diffusive flux of the $\mathrm{i}^{\text {th }}$ species $\left(\mathrm{mol} \cdot \mathrm{m}^{-2} \mathrm{~s}^{-1}\right)$
$\mathrm{Si} \quad$ source of the $\mathrm{i}^{\text {th }}$ species

$D_{f, i} \quad$ molecular diffusion of the $\mathrm{i}^{\text {th }}$ species

$\tau_{F, i} \quad$ tortuosity of the $\mathrm{i}^{\text {th }}$ species

$c_{i} \quad$ concentration of the $i^{\text {th }}$ species $\left(\mathrm{mol} / \mathrm{m}^{3}\right)$

$\mu \quad$ dynamic viscosity (Pa.s)

$\mathrm{t}$ time (s)

$c_{p} \quad$ specific heat capacity in a constant pressure (J/kg.K)

\section{GREEK LETTERS}

$\rho \quad$ density of fluid $\left(\mathrm{kg} / \mathrm{m}^{3}\right)$

$\tau \quad$ viscos stress tensor $(\mathrm{Pa})$

$\alpha_{p} \quad$ coefficient of thermal expansion $(1 / \mathrm{K})$

$\mathrm{q}$ heat flux by conduction $\left(\mathrm{W} / \mathrm{m}^{2}\right)$

$\mathrm{k}$ permeability $\left(\mathrm{m}^{2}\right)$

$\varepsilon_{\mathrm{p}} \quad$ porosity

$\beta_{\mathrm{F}} \quad$ Forchheimer drag coefficient $\left(\mathrm{kg} / \mathrm{m}^{4}\right)$

$\mathrm{u} \quad$ inflow velocity vector $(\mathrm{m} / \mathrm{s})$ 